\title{
Hormone Imbalance in Women with Infertility Caused by Polycystic Ovary Syndrome: Is There a Connection with Body Mass Index?
}

\author{
Mariya Khmil, Stefan Khmil, Mariya Marushchak* \\ I. Horbachevsky Ternopil National Medical University, Ternopil, Ukraine
}

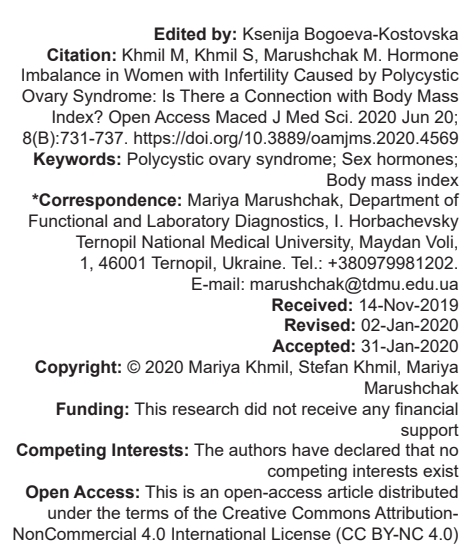

Introduction

Infertility is a common disorder that has a considerable socioeconomic impact on populations while deeply affecting personal health and quality of life of individuals [1]. In Ukraine, according to the national Ministry of Health 2002-2012 data, 12.5 thousand women were diagnosed with infertility each year (122.8 $\pm 0.33 / 100,000$ women) [2]. Conditions such as ovulatory disorders, endometriosis, chromosomal abnormalities, fallopian tubal disease, unexplained infertility, and spermrelated factors can all result in infertility [3], [4]. The reproductive system of both men and women can be affected by untreated sexually transmitted infections, with Chlamydia trachomatis and Neisseria gonorrhoeae being the most common STIs resulting in infertility [5], [6].

However, the most common cause of female infertility is ovulation disorders, and the most common non-ovulatory cause is polycystic ovary syndrome (PCOS) [1]. PCOS is a complex hormonal and metabolic disorder characterized by oligomenorrhea or amenorrhea, hyperandrogenism, and infertility [7]. According to Joham et al., the prevalence of PCOS varies from $6 \%$ to $21 \%$, depending on the diagnostic criteria and studied population [8]. Thus, using the diagnostic criteria proposed by the National Institute of Child Health and Human Development (NICHD, USA) and the American National Institute of Health $(\mathrm{NIH}$, USA), the prevalence of PCOS is $4-8 \%$ among women of reproductive age, while according to the Rotterdam criteria, about $18 \%$ of women have PCOS [9].

The main pathophysiological components of PCOS are gonadotropic dysfunction and insulin resistance, which are often associated with high body mass index (BMI) [10]. Overweight or obesity is diagnosed in approximately $60-80 \%$ of PCOS patients [11]. Although many obese women are fertile, high BMI contributes to an increased risk of fertility disorders. Obesity is a recognized cause of menstrual and ovulation disorders and infertility [12]. Since obesity exacerbates the hormonal and clinical features of PCOS and women suffering from PCOS have a high risk of obesity [13], we suggest that hormonal imbalance resulting in certain body features can be linked to the pathogenesis of PCOS.

The aim of the study was to define the reproductive hormone levels in women with infertility due to PCOS, depending on the BMI. 


\section{Materials and Methods}

The study involved 100 women aged 25-39 years with infertility due to PCOS (PCOS group) and 30 women of the same age with infertility due to tubalperitoneal causes (control group), who were treated at "The Clinic of Professor Stefan Khmil" medical center from October 2015 to March 2019. The study protocol was approved by the Medical Ethics Committees of I. Horbachevsky Ternopil National Medical University (No. 34-25/10/2019) and the study was conducted in accordance with the Helsinki Declaration of 1975 , as revised in 1983. Informed consent was obtained from all patients.

Infertility due to PCOS was diagnosed according to the Rotterdam criteria [9]: Menstrual dysfunction (presence of oligoovulation, anovulation resulting in amenorrhea, oligomenorrhea, and opsomenorrhea) or anovulation; clinical and/or biochemical signs of hyperandrogenism; and polycystic ovaries confirmed by ultrasound. The presence of at least two of the three manifestations results in PCOS diagnosis. The retrospective analysis group did not include patients with adenomyosis, genital endometriosis, and uterine fibromyoma (submucous, subserous, or intramural types). The cases of tubal-peritoneal infertility were diagnosed by laparoscopy or hysterosalpingography.

The height and body weight were measured using standard procedures with a stadiometer and scales, respectively. WC was measured between the ridges of iliac bones and the edge of rib arches at the end of exhalation in normal breathing. $\mathrm{HC}$ was measured at the point of maximum buttocks circumference in a horizontal position. BMI was calculated using the formula BMI $=$ Body weight $(\mathrm{kg}) /$ height $\left(\mathrm{m}^{2}\right)$. The data were interpreted according to the $\mathrm{WHO}$ recommendations: Normal weight in the range of $18.0-24.9 \mathrm{~kg} / \mathrm{m}^{2}$; overweight (pre-obesity), $25.0-29.9 \mathrm{~kg} / \mathrm{m}^{2}$; Class 1 obesity, 30.0 $34.9 \mathrm{~kg} / \mathrm{m}^{2}$; Class 2 obesity, $35.0-39.9 \mathrm{~kg} / \mathrm{m}^{2}$; and Class 3 obesity, $>40 \mathrm{~kg} / \mathrm{m}^{2}$ [14].

The levels of gonadotropin and sex hormones were determined by the laboratory of "The Clinic of Professor Stefan Khmil" medical center (accreditation number 268604/2019). Basal levels of folliclestimulating hormone (FSH) (catalog number EIA-1288), luteinizing hormone (LH) (catalog number EIA1289), estradiol (catalog number EIA-4399), general testosterone (catalog number EIA-1559), anti-Müllerian hormone (AMH) (catalog number DSL-10-14400), and prolactin (catalog number EIA-1291) were determined on days 1-3 and progesterone levels on days 21-22 of the menstrual cycle. Hormone levels in blood serum were determined by ELISA using the "Diagnostic Systems Laboratories, Inc." test systems (USA) and "DRG Diagnostics" (Germany).

Statistical analysis of the results was carried out using Microsoft Office Excel and Statistica 7.0 software. Normality of distributions in each of the study groups was determined using nomograms, ShapiroWilk, and Lilliefors tests. For the groups with values obeying with normal distribution, central tendency values were expressed as a mean $\pm \mathrm{SD}$. For the groups with values not following the normal distribution, central tendency was expressed as a median (M), followed by lower and upper quartiles (LQ; UQ). To determine the impact of each factor on infertility, we constructed frequency tables and performed Fisher's exact test. Probability $p<0.05$ was considered as significant. The analysis of three more normally distributed variables was carried out using ANOVA followed by the Tukey's range test for subsequent pairwise comparison of groups.

\section{Results}

In women with infertility due to PCOS, the levels of anti-Müllerian and luteinizing hormones, estradiol, and testosterone were elevated compared to the control group. At the same time, the concentration of $\mathrm{FSH}$ was significantly reduced (by $35.9 \%$ ) (Table 1). The LH/FSH ratio used in clinical practice is used, was significantly higher (1.5 times) in the patients with PCOS compared to the control group. This indicates a pronounced ovulatory reserve and is a risk factor for ovarian hyperstimulation syndrome [15].

Table 1: Sex hormone levels and LH/FSH ratio in patients with infertility caused by PCOS, M (LQ; UQ)

\begin{tabular}{|c|c|c|c|}
\hline Hormones & Control group & PCOS group & $\begin{array}{l}\text { Mann-Whitney } \\
\text { confidence interval, } \mathrm{p}\end{array}$ \\
\hline $\mathrm{AMH}, \mathrm{nmol} / \mathrm{L}$ & $2.10(1.80 ; 2.30)$ & $6.85(5.30 ; 8.70)$ & $<0.001^{*}$ \\
\hline $\begin{array}{l}\mathrm{FSH}, \mathrm{IU} / \mathrm{L} \text { (days } 2-3 \\
\text { of } \mathrm{MC} \text { ) }\end{array}$ & $8.70(8.40 ; 9.10)$ & $6.40(6.10 ; 7.15)$ & $<0.001^{*}$ \\
\hline $\begin{array}{l}\mathrm{LH}, \mathrm{IU} / \mathrm{L} \text { (days } 2-3 \\
\text { of } \mathrm{MC} \text { ) }\end{array}$ & $7.25(7.00 ; 7.70)$ & $8.35(7.40 ; 9,40)$ & $<0.001^{*}$ \\
\hline LH/FSH & $0.81(0.80 ; 0.90)$ & $1.19(1.09 ; 1.36)$ & $<0.001^{*}$ \\
\hline $\begin{array}{l}\text { Prolactin, } \mu \mathrm{g} / \mathrm{L} \text { (days } \\
2-3 \text { of } \mathrm{MC} \text { ) }\end{array}$ & $\begin{array}{l}13.05(12.40 \\
14.00)\end{array}$ & $12.50(10.95 ; 13.95)$ & $>0.05$ \\
\hline $\begin{array}{l}\text { Estradiol, } \mathrm{pg} / \mathrm{L} \text { (days } \\
2-3 \text { of } \mathrm{MC} \text { ) }\end{array}$ & $\begin{array}{l}27.20(26 ., 80 ; \\
28.40)\end{array}$ & $28.10(27.30 ; 32.40)$ & $<0.05^{\star}$ \\
\hline $\begin{array}{l}\text { Progesterone, } \mathrm{ng} / \mathrm{L} \\
\text { (days } 21-23 \text { of } \mathrm{MC} \text { ) }\end{array}$ & $\begin{array}{l}14,15(13.50 \\
15.30)\end{array}$ & $13.85(12.80 ; 15.15)$ & $>0.05$ \\
\hline $\begin{array}{l}\text { Testosterone, } \mathrm{nmol} / \mathrm{L} \\
\text { (days } 2-3 \text { of } \mathrm{MC} \text { ) }\end{array}$ & $1.40(1.30 ; 1.80)$ & $3.70(1.95 ; 4.75)$ & $<0.001^{*}$ \\
\hline
\end{tabular}
Polycystic ovary syndrome, LQ; UQ: Lower and upper quartiles.

In this study, 42 patients had normal weight (95\% Cl [32.79; 51.80]), and 58 were overweight or obese to various classes: 0 (overweight) $-24 \%$ (95\% Cl [16.64; 33.29]), Class 1 obesity -16\% (95\% Cl [9.99; 24.53]), Class 2 obesity $-13 \%$ (95\% Cl [7.62; 21.12]), and Class 3 obesity $-5 \%(95 \% \mathrm{Cl}[1.87 ; 11.46])$. We detected a correlation between BMI and sex hormone levels (FSH, prolactin, estradiol, and testosterone) as well as LH/FSH ratio (Table 2). Notably, the ratio of $\mathrm{LH} / \mathrm{FSH}$ in women with PCOS was significantly different compared to the control group, while at the same time, PCOS was significantly more frequent in overweight 
Table 2: The levels of reproductive hormones and the LH/FSH ratio depending on BMI in women with infertility due to PCOS (M (LQ; UQ)

\begin{tabular}{|c|c|c|c|c|c|}
\hline Groups & 1 & 2 & 3 & 4 & 5 \\
\hline Indicators & Normal body weight & Overweight & Class 1 obesity & Class 2 obesity & Class 3 obesity \\
\hline AMH & $6.75(5.40 ; 8.30)$ & $7.30(5.80 ; 10.30)$ & $6.50(4.95 ; 8.35)$ & $6.40(6.10 ; 10.10)$ & $6.20(5.00 ; 6.30)$ \\
\hline $\mathrm{FSH}$ & $6.80(6.20 ; 8.00)$ & $6.40(6.20 ; 6.90)$ & $6.45(6.20 ; 7.10)$ & $6.00(6.00 ; 6.10)$ & $6.20(6.00 ; 6.30)$ \\
\hline LH & $7.85(7.00 ; 9.10)$ & $8.60(7.95 ; 9.45)$ & $8.90(7.85 ; 10.85)$ & $9.00(8.20 ; 9.70)$ & $8.30(7.90 ; 11.70)$ \\
\hline Prolactin & $11.55(7.00 ; 12.80)$ & $12.75(12.00 ; 13.75)$ & $16.30(12.50 ; 18.35)$ & $12.40(12.20 ; 12.70)$ & $14.50(14.10 ; 14.50)$ \\
\hline Estradiol & $27.85(26.70 ; 29.30)$ & $28.40(27.10 ; 29.30)$ & $28.95(28.35 ; 34.70)$ & $35.60(28.40 ; 36.30)$ & $35.80(34.20 ; 35.90)$ \\
\hline Progesterone (day $21-23$ of $\mathrm{MC}$ ) & $13.95(12.80 ; 15.20)$ & $13.75(12.75 ; 14.20)$ & $13.55(12.70 ; 14.70)$ & $14.50(12.80 ; 15.30)$ & $15.20(14.10 ; 15.20)$ \\
\hline Testosterone & $1.95(0.90 ; 3.00)$ & $4.10(3.50 ; 4.70)$ & $4.25(3.65 ; 6.20)$ & $5.20(4.30 ; 6.80)$ & $5.10(5.00 ; 7.30)$ \\
\hline
\end{tabular}

and obese patients compared to those with a BMI in the range of 18.5-24.9. For instance, the LH/FSH ratio was $30.35 \%$ higher in women with Class 2 obesity than in the group of women with normal weight. However, in women with both PCOS and Class 3 obesity, the LH/ $\mathrm{FSH}$ ratio was the lowest among those with a $\mathrm{BMI}$ of 25.0-39.9.

When comparing the level of hormones in patients with infertility caused by PCOS to those with tubal-peritoneal infertility (control group), the decrease in FSH levels was a more important contributor to the high than the increase in LH. Similarly, in women with a BMI of more than 25.0, the change in LH/FSH ratio was mainly driven by the change in FSH (Table 2). Thus, the lowest level of FSH was found in women with infertility due to PCOS and Class 2 obesity, an $11.76 \%$ decrease compared to the group of women with normal weight.

The levels of prolactin in the blood of women with infertility caused by PCOS and Classes 1 and 3 obesity were also significantly higher than in the group of women with normal weight. Hyperprolactinemia in PCOS is most often associated with increased levels of metabolic estrogens. Estradiol levels in the blood serum were significantly higher in obese women with infertility caused by PCOS compared to women with normal weight. Thus, estradiol levels in women with PCOS and Class 3 obesity were $28.55 \%$ higher compared to women with normal body weight and $26.06 \%$ compared to overweight women (Table 2).

Testosterone levels in women with infertility caused by PCOS and with a BMI of more than $25.0 \mathrm{~kg} / \mathrm{m}^{2}$ were significantly higher compared to the group of women with normal body weight. However, this marker did not demonstrate significant differences in women with different degrees of overweight and obesity (Table 2).

We studied the relationship between BMI and reproductive hormone levels in the patients with PCOS caused infertility. BMI had a weak inverse correlation with FSH levels $(r=-0.28, p<0.05)$, as well as direct correlation with the LH/FSH ratio $(r=0.40, p<0.05)$ and the levels of $\mathrm{LH}(r=0.25, p<0.05)$, prolactin $(r=0.32$, $p<0.05)$, estradiol $(r=0.43, p<0.05)$, and testosterone $(r=0.68, p<0.05)$.

\section{Discussion}

Since obesity exacerbates the hormonal and clinical features of PCOS and women suffering from PCOS have a high risk of obesity [13], we analyzed the level of hormones relative to $\mathrm{BMI}$ in women with infertility due to PCOS. In our study, $42 \%$ of women with infertility caused by PCOS had normal body weight. According to Gambineri et al., only 33-50\% of women with PCOS are overweight or obese, so obesity is not the only factor affecting the prevalence or severity of PCOS [16]. On the one hand, obese women have a higher risk of developing PCOS [17]. At the same time, women with PCOS have a higher risk of developing obesity [18]. Therefore, it remains unclear whether obesity leads to PCOS, or, conversely, PCOS leads to obesity.

$\mathrm{AMH}$ is a glycoprotein that is synthesized by the granular cells of small antral and periantral ovarian follicles. Serum AMH levels strongly correlate with the number of antral follicles and are more strongly associated with ovarian reserve than $\mathrm{FSH}$ or estradiol [19]. Our findings indicate that serum $\mathrm{AMH}$ levels in women with PCOS increase, corroborating results of other studies [20]. This is probably due to an increase in the number of small antral follicles in PCOS. Diwailly argues that serum $\mathrm{AMH}$ levels are one of the main markers of PCOS [21]. Any of the factors that disrupt the functioning of granular cells, including obesity, can affect the production of AMH [22], [23]. The relationship between serum $\mathrm{AMH}$ and $\mathrm{BMI}$ still remains unclear. Some researchers found a weak negative correlation between serum $\mathrm{AMH}$ concentration and $\mathrm{BMI}$ in women with PCOS [24], [25], but, after correcting for age, this relationship disappeared. Our results are consistent with no correlation between AMH and BMI [26], [27]. It is worth noting that scientists who found a negligible effect of metabolic status on serum AMH levels in PCOS do not recommend considering $\mathrm{BMI}$ when interpreting $\mathrm{AMH}$ levels in clinical practice [28]. Changes in serum AMH in women with PCOS are mainly associated with impaired production of gonadotropins and steroid hormones. We found a significant decrease in $\mathrm{FSH}$ and an increase in $\mathrm{LH}$ levels in obese patients with PCOS. There is also a weak inverse relationship between $\mathrm{BMI}$ and $\mathrm{FSH}$ and weak direct relationship between BMI and LH levels. These 
data can be confirmed by a significantly higher ratio of $\mathrm{LH} / \mathrm{FSH}$ in patients with PCOS. Literature presents controversial conclusions on the changes to $\mathrm{LH}, \mathrm{FSH}$, and $\mathrm{LH} / \mathrm{FSH}$ ratio in PCOS and obesity. Banaszewska et al. did not find significant differences between LH/FSH ratio means in the groups of women with and without PCOS [29]. Another study found elevated LH/FSH ratio in patients with PCOS, notably with no correlation to age and BMI [30]. A study by Esmaeilzadeh et al. showed that specific age ( $\geq 35$ years), BMl $\left(\geq 25 \mathrm{~kg} / \mathrm{m}^{2}\right)$, and acne were significant indicators of metabolic disorders (including obesity) in women with PCOS [31]. Studies confirm the relationship between $\mathrm{LH}$, weight, and PCOS: Insler et al. reported that in women with PCOS and normal body weight, blood serum levels were significantly higher compared to patients with obesity, while Yanira et al. found an inverse correlation between $\mathrm{LH}$ and $\mathrm{BMI}$ in women with PCOS [32], [33]. A study by Alnakash and Al-Tae'e showed an inverse relationship between FSH and BMI in obese women with PCOS [34], which our study confirms. The pathological secretion of gonadotropin in $\mathrm{PCOS}$ results in elevated serum LH levels and increased $\mathrm{LH} / \mathrm{FSH}$ ratio [35]. An increase in gonadotropin-releasing hormone upregulates transcription of the $\mathrm{LH} \beta$-subunit through the FSH $\beta$-subunit, which leads to an increase in the LH/FSH ratio in PCOS patients [36].

This study found that in patients with PCOS, testosterone levels significantly increase $(p<0.001)$. At the same time, testosterone levels are the lowest in PCOS patients with normal body weight compared to overweight/ obesity $(p<0.05)$, and they significantly correlate with the type of obesity [37]. Nevertheless, the findings on the effect of obesity on the production of androgens in blood serum in PCOS are contradictory. Moran et al. report that testosterone and androstenedione levels in PCOS patients are not connected with BMI [11]. However, obesity produces a decrease in sexual hormone-binding globulin, increasing free androgens levels [38]. Another study indicates that obesity causes an increase in testosterone levels in PCOS patients [39], which confirms the results of our study. There is a broad agreement that women with PCOS experience an increase in visceral and subcutaneous fat accumulation caused by an increased rate of androgen production [40]. Furthermore, Escobar-Morreale et al. suggest that genetic or induced excess of testosterone may be the main cause of obesityassociated with PCOS [41]. On the other hand, Balen et al. found the same metabolic disorders in women with PCOS and normal body weight as in obese patients [42].

The data on the causative relationship between hyperprolactinemia and PCOS remain inconclusive. Some authors believe that hyperprolactinemia in PCOS is associated with hyperestrogenism and steroidogenesis disorders, while others consider hyperprolactinemia to be one of the factors that underlie the pathogenesis of PCOS [43], [44]. The apparent connection of hyperprolactinemia with PCOS can be explained by high LH levels in women with PCOS, leading to a secondary decrease in dopaminergic tone, causing elevated prolactin levels. Another model proposes that increased prolactin secretion under PCOS is the effect of hyperestrogenemia [45]. Finally, a study by Delcour et al., as well as our data, does not show any connection between the prolactin levels and PCOS [44]. However, there a link between obesity and pathogenesis of hyperprolactinemia: In obese women, the spontaneous release of prolactin was significantly intensified and correlated with the size of visceral adipose tissue [46]. Studies also suggest that decreased circulating leptin/ estrogen levels can reduce prolactin levels. Our results underscore the correlation between prolactin levels and BMI, with significantly higher prolactin levels found in women with the android type of obesity. However, it remains unclear whether hyperprolactinemia association with the weight gain is due to the stimulation of lipogenesis or due to dysregulation of the dopaminergic tone of the central nervous system [47].

Our study found a small but significant increase in serum estradiol levels in PCOS patients. The literature on the levels of estradiol in PCOS is inconclusive. Anovulation is associated with low estradiol secretion, mainly due to peripheral extraglandular conversion and minimal progesterone production [48]. Hashemi et al. found decreased estradiol levels in PCOS, while studies point out to exceedingly high estradiol levels [49], [50]. The increase in the level of bioavailable estradiol in PCOS can be attributed to reduced sex hormone-related globulin levels [51], which are also associated with obesity and testosterone levels [38]. Estrogens known to normalize body weight and glucose homeostasis, preventing obesity [52]. Although high levels of estradiol can prevent the development of obesity, traditionally, obesity characterized by relative hyperestrogenemia [53]. In our study, the level of estradiol correlated with BMI. These results suggest estradiol-mediated dysregulation of adipose tissue formation or a decrease in sensitivity to estradiol.

There are some limitations in our study, the most important is relatively small sample size. This can affect the significance of some results, and we suggest that additional research is needed to confirm our findings.

In our study, hormone levels were measured by ELISA method. However, liquid chromatography/mass spectrometry (LC/MS) is considered a working standard for sex steroid assay because of its high sensitivity and ability to detect even the lowest concentrations of the hormones.

\section{Conclusions}

We found a hormonal imbalance in women with infertility caused by PCOS: increased levels of 
anti-Müllerian and luteinizing hormones, estradiol, and testosterone and decreased FSH levels. Analysis of the relationship between the concentration of reproductive hormones and BMI showed a weak inverse relationship between $\mathrm{BMI}$ with $\mathrm{FSH}$ levels, as well as a direct correlation with the levels of $\mathrm{LH}$, prolactin, estradiol, and testosterone, and $\mathrm{LH} / \mathrm{FSH}$ ratio. Thus, obesity exacerbates the hormonal imbalance in women with infertility caused by PCOS.

\section{Data Availability}

The data of this study are available by request.

\section{Authors' Contributions}

Stefan Khmil contributed to study design, Mariya Khmil conducted research, data, and statistical analysis, and Mariya Marushchak supported in interpretation of findings and drafting of the manuscript.

\section{References}

1. Moridi A, Roozbeh N, Yaghoobi H, Soltani S, Dashti S, Shahrahmani N, et al. Etiology and risk factors associated with infertility. Int J Women's Health Reprod Sci. 2019;7(3):346-53. https://doi.org/10.15296/ijwhr.2019.57

2. Timchenko OI, Mykytenko DO, Koba OP, Lynchak OV. Level of infertility in regions according to ministry of public health data. Med Perspect. 2014;19(3):105-11. https://doi. org/10.26641/2307-0404.2014.3.30414

3. Kalima-Munalula MN, Ahmed Y, Vwalika B. Factors associated with infertility among women attending the gynaecology clinic at university teaching hospital, Lusaka, Zambia. Med J Zambia. 2017;44(1):41-4.

4. Koval HD, Chopyak VV, Kamyshnyi OM, Kurpisz MK. Transcription regulatory factor expression in T-helper cell differentiation pathway in eutopic endometrial tissue samples of women with endometriosis associated with infertility. Cent Eur J Immunol. 2018;43(1):90-6. https://doi.org/10.5114/ ceji.2018.74878

PMid:29736151

5. Nelson HD, Zakher B, Cantor A, Deagas M, Pappas M Screening for gonorrhea and Chlamydia: A systematic review for the U.S. preventive services task force. Ann Intern Med. 2014;161(12):884-93. https://doi.org/10.7326/m14-1022 PMid:25244000

6. Boiko I, Golparian D, Krynytska I, Bezkorovaina H, Frankenberg A, Onuchyna M, et al. Antimicrobial susceptibility of Neisseria gonorrhoeae isolates and treatment of gonorrhoea patients in Ternopil and Dnipropetrovsk regions of Ukraine, 2013-2018. APMIS. 2019;127(7):503-9. https://doi.org/10.1111/apm.12948
7. Zhou J, Yang L, Yu J, Wang Y, Liu Z. Efficacy of acupuncture on menstrual frequency in women with polycystic ovary syndrome: Protocol for a randomized, controlled trial. Medicine. 2017;96(47):e8828. https://doi.org/10.1097/ md.0000000000008828

\section{PMid:29381988}

8. Joham AE, Teede HJ, Ranasinha S, Zoungas S, Boyle J. Prevalence of infertility and use of fertility treatment in women with polycystic ovary syndrome: Data from a large communitybased cohort study. J Womens Health. 2015;24:299-307. https://doi.org/10.1089/jwh.2014.5000

PMid:25654626

9. The Rotterdam ESHRE/ASRM-sponsored PCOS Consensus Workshop Group. Revised 2003 consensus on diagnostic criteria and long-term health risks related to polycystic ovary syndrome (PCOS). Hum Reprod. 2004;19(1):41-7. https://doi. org/10.1093/humrep/deh098

PMid: 14688154

10. Krynytska IY, Marushchak MI. The indices of nitrogen (II) oxide system in experimental hepatopulmonary syndrome. Ukr Biochem J. 2018;90(5):91-7. https://doi.org/10.15407/ ubj90.05.091

11. Moran C, Arriaga M, Rodriguez G, Moran S. Obesity differentially affects phenotypes of polycystic ovary syndrome. Int J Endocrinol. 2012;2012:317241. https://doi.org/10.1155/2012/317241 PMid:22829818

12. Suturina LV, Atalyan AV, Darzhaev ZY, Belenkaya LV, Baldano MN, Lazareva LM. Overweight and obesity prevalence in referral population of infertile women with polycystic ovary syndrome. Adv Obes Weight Manag Control. 2017;7(1):237-40. https://doi.org/10.15406/aowmc.2017.07.00188

13. Johnston BC, Zeraatkar D, Han MA, Vernooij RW, Valli C, El Dib R, et al. Unprocessed red meat and processed meat consumption: Dietary guideline recommendations from the nutritional recommendations (NutriRECS) consortium. Ann Intern Med. 2019:171(10):756-64. https://doi.org/10.7326/ m19-1621

PMid:31569235

14. Department of Health and Human Department of Health and Human Services, Centers for Disease Control and Prevention. Body Mass Index: Considerations for Practitioners; 2019. Available from: https://www.cdc.gov/obesity/downloads/ bmiforpactitioners.pdf. [Last accessed on 2019 Sep 12].

15. Fiedler K, Ezcurra D. Predicting and preventing ovarian hyperstimulation syndrome (OHSS): The need for individualized not standardized treatment. Reprod Biol Endocrinol. 2012;10:32. https://doi.org/10.1186/1477-7827-10-32

PMid:22531097

16. GambineriA, Pelusi $C$, Vicennati V, PagottoU, Pasquali R. Obesity and the polycystic ovary syndrome. Int J Obes Relat Metab Disord 2002;26(7):883-96. https://doi.org/10.1038/sj.ijo.0801994 PMid: 12080440

17. Pasquali R, Stener-Victorin E, Yildiz BO, Duleba AJ, Hoeger K Mason $\mathrm{H}$, et al. PCOS forum: Research in polycystic ovary syndrome today and tomorrow. Clin Endocrinol. 2011;74(4):42433. https://doi.org/10.1111/j.1365-2265.2010.03956.x PMid:21158892

18. Randeva HS, Tan BK, Weickert MO, Lois K, Nestler JE, Sattar N, et al. Cardiometabolic aspects of the polycystic ovary syndrome. Endocr Rev. 2012;33(5):812-41. https://doi. org/10.1210/er.2012-1003 PMid:22829562

19. Eldar-Geva T, Margalioth EJ, Gal M, Ben-Chetrit A, Algur N, Zylber-Haran E, et al. Serum anti-mullerian hormone levels during controlled ovarian hyperstimulation in women with polycystic ovaries with and without hyperandrogenism. Hum 
Reprod. 2005;20(7):1814-9. https://doi.org/10.1093/humrep/ deh873

\section{PMid: 15802320}

20. Laven JS, Mulders AG, Visser JA, Themmen AP, De Jong FH, Fauser BC. Anti-Mullerian hormone serum concentrations in normoovulatory and anovulatory women of reproductive age. J Clin Endocrinol Metab. 2004;89(1):318-23. https://doi. org/10.1210/jc.2003-030932

PMid: 14715867

21. Dewailly D. Diagnostic criteria for PCOS: Is there a need for a rethink? Best Pract Res Clin Obstet Gynaecol. 2016;37:5-11. PMid:27151631

22. Comninos AN, Jayasena CN, Dhillo WS. The relationship between gut and adipose hormones, and reproduction. Hum Reprod Update. 2014;20(2):153-74. https://doi.org/10.1093/ humupd/dmt033

PMid:24173881

23. Marushchak M, Krynytska I, Milevska L, Miz A, Mialiuk O. The changes of activity of effector caspase cascade components in case of alimentary obesity in rats. Bangladesh J Med Sci. 2017;16(2):252-8. https://doi.org/10.3329/bjms.v16i2.31280

24. Cui Y, Shi Y, Cui L, Han T, Gao X, Chen ZJ. Age-specific serum antimüllerian hormone levels in women with and without polycystic ovary syndrome. Fertil Steril. 2014;102(1):230-6. https://doi.org/10.1016/j.fertnstert.2014.03.032

PMid:24746743

25. Kriseman M, Mills C, Kovanci E, Sangi-Haghpeykar $H$, Gibbons W. Anti mullerian hormone levels are inversely associated with body mass index (BMI) in women with polycystic ovary syndrome. J Assist Reprod Genet. 2015;32(9):1313-6. https://doi.org/10.1007/s10815-015-0540-0 PMid:26238387

26. Pigny $\mathrm{P}$, Merlen E, Robert $\mathrm{Y}$, Cortet-Rudelli C, Decanter C, Jonard $\mathrm{S}$, et al. Elevated serum level of anti-mullerian hormone in patients with polycystic ovary syndrome: Relationship to the ovarian follicle excess and to the follicular arrest. $\mathrm{J}$ Clin Endocrinol Metab. 2003;88(12):5957-62. https://doi. org/10.1210/jc.2003-030727

PMid:14671196

27. Skałba P, Cygal A, Madej P, Dabkowska-Huc A, Sikora J, Martirosian G, et al. Is the plasma anti-müllerian hormone $(\mathrm{AMH})$ level associated with body weight and metabolic, and hormonal disturbances in women with and without polycystic ovary syndrome? Eur J Obstet Gynecol Reprod Biol. 2011;158(2):254-9. https://doi.org/10.1016/j.ejogrb.2011.06.006 PMid:21752527

28. Lefebvre T, Dumont A, Pigny P, Dewailly D. Effect of obesity and its related metabolic factors on serum anti-müllerian hormone concentrations in women with and without polycystic ovaries. Reprod Biomed Online. 2017;35(3):325-30. https://doi. org/10.1016/j.rbmo.2017.05.013

PMid:28624344

29. Banaszewska B, Spaczynski RZ, Pelesz M, Pawelczyk L. Incidence of elevated $\mathrm{LH} / \mathrm{FSH}$ ratio in polycystic ovary syndrome women with normo-and hyperinsulinemia. Rocz Akad Med Bialymst. 2003;48:131-4

PMid:14737959

30. Fakhoury H, Tamim H, Ferwana M, Siddiqui IA, Adham M, Tamimi W. Age and BMI adjusted comparison of reproductive hormones in PCOS. J Family Med Prim Care. 2012;1(2):132-6. https://doi.org/10.4103/2249-4863.104984 PMid:24479022

31. Esmaeilzadeh S, Andarieh MG, Ghadimi R, Delavar MA. Body mass index and gonadotropin hormones (LH and FSH) associate with clinical symptoms among women with polycystic ovary syndrome. Glob J Health Sci. 2015;7(2):101-6. https://doi. org/10.5539/gjhs.v7n2p101

PMid:25716399

32. Insler V, Shoham Z, Barash A. Polycystic ovaries in none obese and obese patients: Possible pathophysiological mechanism based on new interpretation of facts and findings. Hum Reprod. 1993;8(3):379-84. $\quad$ https://doi.org/10.1093/oxfordjournals. humrep.a138055

33. Yanira LP, Serene SS, Yarisie J, Anne E, Sabrina G, Janet EH Inverse relationship between luteinizing hormone and body mass index in polycystic ovarian syndrome: Investigation of hypothalamic and pituitary contributions. J Clin Endorin Metabol. 2006;91(4):1309-16. https://doi.org/10.1210/jc.2005-2099 PMid: 16434454

34. Alnakash AH, Al-Tae'e NK. Polycystic ovarian syndrome: The correlation between the LH/FSH ratio and disease manifestations. Middle East Fertil Soc J. 2007;12(1):35-40.

35. Fritz MA, Speroff L. Clinical Gynecologic Endocrinology and Infertility. $8^{\text {th }}$ ed. Philadelphia, PA: Lippincott Williams \& Wilkins; 2011. p. 501-18.

36. Park $\mathrm{CH}$, Chun $\mathrm{S}$. Association between serum gonadotropin level and insulin resistance-related parameters in Korean women with polycystic ovary syndrome. Obstet Gynecol Sci. 2016;59(6):498-505. https://doi.org/10.5468/ogs.2016.59.6.498 PMid:27896252

37. Khmil M, Khmil S, Marushchak M. Reproductive hormone metabolism in women with infertility due to polycystic ovary syndrome depending on the constitutional body types. Pol Merkur Lekarski. 2020;48(285):152-6.

PMid:32564037

38. Bergh HT, Berne C, Lithell H. Serum lipoprotein lipid profile in women with the polycystic ovary syndrome: Relation to anthropometric, endocrine and metabolic variables. Clin Endocrinol. 1994;41(4):463-71. https://doi. org/10.1111/j.1365-2265.1994.tb02577.x

\section{PMid:7955457}

39. Moran C, Renteria JL, Moran S, Herrera J, Gonzalez S, Bermudez JA. Obesity differentially affects serum levels of androstenedione and testosterone in polycystic ovary syndrome. Fertil Steril. 2008;90(6):2310-7. https://doi.org/10.1016/j. fertnstert.2007.09.016 PMid:18163993

40. El Hayek S, Bitar L, Hamdar LH, Mirza FG, Daoud G. Polycystic ovarian syndrome: An updated overview. Front Physiol. 2016;7:124. https://doi.org/10.3389/fphys.2016.00124

\section{PMid:27092084}

41. Escobar-Morreale HF, Samino $S$, Insenser $M$, Vinaixa $M$, Luque-Ramírez M, Lasunción MA, et al. Metabolic heterogeneity in polycystic ovary syndrome is determined by obesity: Plasma metabolomic approach using GC-MS. Clin Chem. 2012;58(6):999-1009. https://doi.org/10.1373/ clinchem.2011.176396

PMid:22427353

42. Balen A, Rajkowha M. Polycystic ovary syndrome-a systemic disorder? Best Pract Res Clin Obstet Gynaecol. 2003;17(2):26374. https://doi.org/10.1016/s1521-6934(02)00119-0 PMid:12758099

43. Tatarchuk TF, Gunkov SV, Efimenko OA. Modern approaches to diagnosis and treatment of hyperprolactinemia. Reprod Endocrinol. 2012;1(3):26-44.

44. Delcour C, Robin G, Young J, Dewailly D. PCOS and hyperprolactinemia: WHAT do we know in 2019? Clin Med Insights Reprod Health. 2019;13:1177. https://doi. org/10.1177/1179558119871921

PMid:31523136 
45. Robin G, Catteau-Jonard S, Young J, Dewailly D. Physiopathological link between polycystic ovary syndrome and hyperprolactinemia: Myth or reality? Gynecol Obstet Fertil. 2011;39(3):141-5. https://doi.org/10.1002/uog.11202 PMid:21388855

46. Pereira-Lima JF, Leães CG, Neto FM, Barbosa MV, da Silva AL, Oliveira MC. Hyperprolactinemia and body weight: Prevalence of obesity and overweight in patients with hyperprolactinemia. Res J Endocrinol Metab. 2013;1:2. https:// doi.org/10.7243/2053-3640-1-2

47. Shibli-Rahhal A, Schlechte J. The effects of hyperprolactinemia on bone and fat. Pituitary. 2009;12(2):96-104 https://doi. org/10.1007/s11102-008-0097-3

PMid: 18338266

48. Homer MV, Rosencrantz MA, Shayya RF, Chang RJ. The effect of estradiol on granulosa cellresponses to FSH in women with polycysticovary syndrome. Reprod Biol Endocrinol. 2017;15(1):13. https://doi.org/10.1186/s12958-017-0230-0 PMid:28187771

49. Hashemi AH, Mozdarani $H$, Naghavi A. Comparison of the levels of $\mathrm{LH}$ and $\mathrm{FSH}, \mathrm{TSH}$, prolactin, progesterone and estradiol hormones between Iranian infertile women with polycystic ovary syndrome and healthy women. Int J Med Res Health Sci. 2016;5(12):370-5.

50. Bartolone L, Smedile G, Arcoraci V. Extremely high levels of estradiol and testosterone in a case of polycystic ovarian syndrome. Hormone and clinical similarities with the phenotype of the alpha estrogen receptor null mice. J Endocrinol Invest. 2000;23(7):467-72. https://doi.org/10.1007/bf03343757

PMid:11005272

51. Dumitrescu R, Mehedintu C, Briceag I, Purcarea VL, Hudita D. The polycystic ovary syndrome: An update on metabolic and hormonal mechanisms. J Med Life. 2015;8(2):142-5.

PMid:25866568

52. Clegg D, Hevener AL, Moreau KL, Morselli E, Criollo A, Van Pelt RE, et al. Sex hormones and cardiometabolic health: Role of estrogen and estrogen receptors. Endocrinology. 2017;158(5):1095-105. https://doi.org/10.1210/en.2016-1677 PMid:28323912

53. Colleluori G, Chen R, Napoli N, Aguirre LE, Qualls C, Villareal DT, et al. Fat mass follows a U-shaped distribution based on estradiol levels in postmenopausal women. Front Endocrinol. 2018;9:315. https://doi.org/10.3389/fendo.2018.00315

PMid:30013511 